\title{
APOIO E ACOLHIMENTO A CRIANÇAS E ADOLESCENTES ATRAVÉS DO LÚDICO: CRIANDO ESPAÇOS DE CUIDADO
}

\author{
Supporting and assisting children and adolescents through play activities: \\ creating caring environments
}

Cristina Oliveira ${ }^{1}$

\section{Resumo}

"Estórias Diferentes" é um projeto idealizado pela autora e consiste em estórias para serem lidas por ou para crianças e adolescentes. Tem como objetivo promover um ambiente de cuidado, apresentando personagens com características próprias e diferentes formas de lidar com problemas do dia a dia, em situações nas quais os leitores podem se identificar. As estórias focam percepções, sentimentos e desafios que são enfrentados pelas crianças, muitas vezes subestimados pelos adultos. A inspiração para o Estórias Diferentes veio das experiências pessoais de sua criadora e da demanda existente no Brasil em relação à saúde mental infantojuvenil, visto que ainda há uma escassez de recursos apropriados para essa área. As estórias ocorrem em um elaborado universo ficcional e tomam forma na vida real por meio de bonecos de feltro, máscaras e bonecos de dedo. Estão presentes nas escolas desde 2016, quando se deu o início do projeto "Interatividade na Escola" como metodologia socioeducativa, onde os alunos reforçam o conteúdo pedagógico de forma lúdica. Estórias Diferentes está presente nos trabalhos escolares e atividades integrativas com bonecos e máscaras. Também é dada a oportunidade para que os alunos desenvolvam as suas próprias estórias. É relevante destacar a grande versatilidade do projeto, que pode ser adaptado para diversas situações. Além das escolas, Estórias Diferentes também está presente em associações e consultórios médicos, proporcionando apoio e acolhimento a crianças e adolescentes através de atividades lúdicas.

Palavras-chave: Saúde mental. Educação infantil. Apoio e Acolhimento.

\footnotetext{
${ }^{1}$ Educadora, palestrante e escritora, com atuação integrada em ações sociais. Atuou como dirigente a ABRATA. Criadora do projeto Estórias Diferentes. E-mail: cristinaoliveira@estoriasdiferentes.com.br
} 


\begin{abstract}
"Estórias Diferentes" (Different Stories) is a project created by the author, consisting of stories to be read by or for children and teenagers. Its goal is to promote a caring environment, by presenting characters who go through challenging situations, and are constantly creating solutions to deal with those. This is helpful for readers who might identify with the situations. The stories are centered around children's feelings and perceptions, portraying the challenges that they often go through, but that are normally dismissed by adults. The inspiration for Estórias Diferentes comes from the personal experiences of its creator, but also from the increasing demand for children's mental health resources in Brazil, considering their current scarcity. The stories take place in a fictional universe, and are present in real life through felt dolls and finger puppets. They have been present in schools since 2016, when the project and educational tool "Interatividade na Escola" (Interactivity at School) began. During the project, the students got to learn topics from the syllabus through play activities, which use dolls and masks. They also use resources from Estórias Diferentes on their homework. It is incentivized that the children develop their own stories as well. It is important to highlight the immense versatility of this project, which can be adapted for multiple situations. Besides schools, Estórias Diferentes is also present in associations and medical offices and waiting rooms, providing support and assistance for children and teenagers through play activities.
\end{abstract}

Key-words: Mental health. Child education. Support and assistance.

\title{
O nascimento do projeto Estórias Diferentes
}

Estórias Diferentes é um site para crianças criado em 2012. Com aventuras que podem ser lidas por elas, ou por adultos - para elas. Um site que alerta adultos para que escutem e percebam a criança. Cada personagem tem características próprias e incorpora uma forma de reagir no dia a dia. Uns, com dificuldades efetivas, outros, com falta de limites. Há interação entre eles,abordando temas como solidariedade, empatia e inclusão. Um site com histórias que relatam situações do cotidiano, sob o olhar infantil, com foco nas suas percepções, sentimentos ou desafios muitas vezes imperceptíveis para os adultos, mas de enorme dimensão 
para as crianças; principalmente para aquelas que têm dificuldades de expressar sentimentos.

O projeto foi inspirado pelas experiências pessoais de sua criadora, autora deste artigo, e pela necessidade de maiores recursos destinados à saúde mental de crianças e adolescentes no Brasil. A exemplo disso, Delfini, Bastos e Reis (2017), retratam as dificuldades que famílias encontram ao buscar auxílio psicológico para suas crianças, visto que há uma escassez de recursos na área, e que o modelo de apoio mais utilizado foca apenas nas patologias mentais, isolando o paciente, e explicitando uma demanda de novas formas de abordagem à saúde mental de crianças e adolescentes. É relevante notar que a presença de atividades recreativas na vida das crianças é um fator importante para a proteção de sua saúde mental, o que incentiva a criação de projetos de atividades lúdicas para essa faixa demográfica (MATSUKURA, FERNANDES e CID, 2012). Logo, assim como apontam Taño e Matsukura (2015), há uma luta pela ampliação do cuidado na atenção à saúde mental infantojuvenil atual, e o projeto Estórias Diferentes nasce nesse contexto.

A biografia da autora do projeto é pertinente para compreender a concepção do Estórias Diferentes, assim como apresentado pelo depoimento em primeira pessoa abaixo:

"É indispensável contextualizar esse trabalho - há uma história por detrás das estórias diferentes: há a trajetória de uma criança que sempre se sentiu estranha, tipo um ET adotado! Foram as histórias de fadas contadas pelo meu pai que suavizaram meus medos e inquietações.

Meu pai era dentista - lembro de um livro que fiz e distribuí na sala de espera, para que as crianças não sentissem medo da "Dona Anestesia" ou da "Sra. Broca" que ajudavam a tratar das cáries".

Nessa trajetória há uma quebra muito forte de comportamento - da criança puro medo para militante política nos duros tempos da ditadura. Medo e destemor, convivendo nos altos e baixos até o diagnóstico aos 44 anos do transtorno bipolar do humor.

Ser professora primária, mãe, com uma história de vida intensa, determinaram a forma de enfrentar o desafio de um diagnóstico de transtorno 
mental. A narrativa de vida para qualificar meu trabalho, resultou no livro: "Sou mais que a minha doença - Sonhos, desafios e superação" (Editora Vermelho Marinho fev. 2021).

Enfrento meus demônios internos que hoje tem nome, através da informação e da ação coletiva.

A ação social esteve presente desde a infância, com salas de aula para crianças pobres, projeto junto a Cruz Vermelha para filhos das empregadas domésticas e nos projetos comunitários em Santiago do Chile onde morei por mais de 3 anos.

Trabalho há mais de vinte anos na área de saúde mental, em São Paulo, em instituições como a Associação Brasileira de Familiares, Amigos e Portadores de Transtornos Afetivos - ABRATA ou a "Comunidade de Fala - Contando nossas histórias".

Atuei na ABRATA por mais de 10 anos; fiz parte da diretoria, como secretária geral, vice-presidente e presidente na gestão 2009/2011. Fui coordenadora dos Grupos de Ajuda Mútua - GAM. Na minha gestão, elaboramos uma forma diferenciada de gerenciamento coletivo na diretoria, incorporando as dificuldades inerentes de atuação de alguém com transtorno mental ocasionalmente em surto ou acerto de medicação. Um aprendizado em gestão no terceiro setor. Foi aqui que voltei a ser eu - recuperação da auto estima. Trabalho com foco nos iguais e formação do voluntariado.

$\mathrm{Na}$ Comunidade de Fala o aprendizado foi outro. Primeiro a convivência com pessoas com outras características, outros transtornos mentais. Que aprendizado de vida! E o trabalho saiu de dentro da Associação para focar especificamente um público mais ampliado - desmistificando a saúde mental. Saindo de ser um paciente, para ser sujeito da própria história."

\section{Estórias Diferentes: o projeto}

As estórias diferentes são contos e aventuras que residem em um universo ficcional a Floresta dos Rolls - e tem como objetivo suavizar caminhos, acalmar medos, preparar para uma troca de ideias, consulta, ou aprendizado, tudo isso através do encantamento e diversão.

A Floresta dos Rolls é um espaço ficcional com árvores e frutos estranhos, arbustos exóticos e caminhos incríveis. Tudo muito colorido. Há um mapa da 
Floresta, indicando Regolish, que é a Vila onde vivem as crianças denominadas "pequenos". Junto à Regolish, encontra-se o Recanto Mágico, palco da maior parte das brincadeiras. O Recanto do Sol serve para brincadeiras, mas principalmente troca de ideias e conversas com pais e cuidadores. Há também o Canto Sombrio. Mesmo na magia e encantamento, são encontrados cantos sombrios, tristeza e medo. E há também a Biblioteca - é de lá que surge o incentivo à leitura e pesquisa; espaço para atividades culturais e abertura para novas formas de comunicação do site, como podcast, músicas etc.

Os personagens são figuras desenhadas. Também foram criados bonecos de feltro com 4 expressões cada - alegre, triste, irritado, assustado. Há dois bonecos por personagem e frente e verso para apresentarem as 4 expressões Foram confeccionadas máscaras de cada um dos personagens com as 4 expressões. E há também os "dedoches" (bonecos dos personagens para colocar nos dedos).

Algumas estórias foram criadas para a sala de espera de médicos. Em um consultório de ortopedia infantil, havia uma coleção de desenhos para colorir com os personagens em situações que preparavam o paciente para falar onde doía e a escala de dor.

A pedido de uma psiquiatra, foi criada a personagem Nina para estar junto no lançamento de um livro sobre TDAH (Transtorno do Déficit de Atenção e Hiperatividade). Ela tem todas as características descritas no livro.

\section{Estórias Diferentes: o trabalho com as crianças}

É importante destacar que a validação do projeto Estórias Diferentes vem através de ações diretamente ligadas às crianças.

Em 2016 iniciou-se o Projeto Interatividade na Escola - uma ação das Estórias Diferentes para o público infantil, onde personagens saltam do universo mágico da Floresta dos Rolls, para o mundo real.

Aqui entra a importância da experiência de vida, profissional e do conhecimento adquirido nas associações de apoio à saúde mental por parte da autora do projeto, assim como fica evidente no depoimento abaixo:

"Se na ABRATA conquistei ser e conhecer a Cristina, na Comunidade de Fala dei asas à minha habilidade e experiência para levar ao público sonhos, desafios e superação. 
No primeiro semestre de 2016, estive no Colégio Estadual Fagundes dos Reis, em Passo Fundo RS, em uma classe de deficientes auditivos, a maioria com transtornos mentais. Idades variando de 8 a 16 anos. Muitos vivem em casas de acolhida - foram abandonados. Eles frequentam séries iniciais e se alfabetizam em: L1 - LIBRAS: língua brasileira de sinais; L2 - português: como segunda língua, em uma sala específica para eles.

Após essa alfabetização e adaptação, são incluídos em salas regulares, pois há uma equipe de professores intérpretes e professores surdos. O Colégio tem uma parceria com a Universidade de Passo Fundo que fornece estagiários para apoiar esse trabalho.

Foram 2 dias de visita onde contei estórias do meu site, com o computador ligado, mostrando os cenários. A professora traduziu em libras o que eu falava. Os desenhos muito coloridos e diferentes, encantaram as crianças. Brincaram com os bonecos e me abraçaram e riram muito. Magia pura!

A equipe de professoras fez uma brincadeira comigo - fui passar a tarde com duas turmas sem nenhuma avaliação de transtorno mental, mas consideradas os terríveis do Colégio. "jogaram-me às feras". Foi uma das mais belas experiências teatrais que tive. Eles incorporaram os personagens e criaram peças teatrais divertidas e agitadas.

O contato com o Colégio Fagundes dos Reis foi através da professora Rosamaria Azeredo, pedagoga, pós-graduada em Educação Especial da Universidade de Passo Fundo - UPF e especialista na educação de surdos formada pelo Instituto Nacional Educação de Surdos Rio de Janeiro. Nos dois dias de visita, tive um encontro que me impressionou pela grandiosidade daquelas profissionais, seja pela acolhida da direção, seja pelo foco da conversa: os alunos com dificuldades ou necessidades especiais como diziam. Não escutei nenhum desabafo, pelo contrário, o "como posso ajudar mais", predominou. Trocar ideias e principalmente aprender com essas profissionais foi uma dádiva.

No segundo semestre de 2016, desenvolvi o projeto Interatividade na Escola, aplicando uma metodologia socioeducativa, integrada ao projeto pedagógico do semestre. $O$ trabalho foi com o 20 e 50 ano fundamental da Escola Estadual Plácido de Castro, em Porto Alegre - RS, a convite da professora Maria Lúcia Duarte do 50 ano, tendo a colaboração da professora Isabel Coelho, do 20 ano. O tema foi: "Conhecendo o Rio Grande do Sul com novos amigos". 
Efetivamente fizemos o elo entre ficção e realidade. Descrever o momento é fácil. Difícil mesmo é conseguir transmitir a magia que ocorreu com essas crianças naquele semestre de 2016. Foram 2 meses de pesquisa dos alunos e contato com os personagens, via Skype. Cada um escolheu seu personagem preferido. Criei material de apoio que era impresso na escola. Finalizamos as atividades com um evento presencial de 2 dias.

Iniciei contando estórias, apresentando o livro elaborado para eles, já conhecido nos encontros à distância. Depois brincamos com a versão do ônibus que foi o elo do mundo mágico e a realidade deles. Um ônibus de papelão, com janelas onde colocávamos "palitinhos" (como se fosse um picolé), com fotos de cada um deles e dos personagens. Imaginação solta nas narrações e interações de alunos e personagens dentro do ônibus.

Os alunos apresentaram cantos e danças do folclore gaúcho e interpretaram os personagens com um rap que idealizaram sem a professora. Fica claro a identificação dos personagens e o "saltar da caixinha", com a criatividade em alta. Alegria no processo. Houve a brincadeira de contornar o corpo em papel no chão e com desenhos dentro dele, expressando gostos e sentimentos - amigos se conhecendo.

Foi realizada a Feira Literária da Escola com mostra de artesanato e lançamento do material de pesquisa sobre o Rio Grande do Sul junto com personagens das Estórias Diferentes. Cada aluno teve um livro publicado. Um dos artesanatos trabalhados, foi o encontrar um galho seco e cobri-lo com as mais diversas fitas e cores - aprendizado do trabalho: podemos enfeitar, transformar algo seco e retorcido. Um dos pontos mais altos do encontro: teatro dos sentimentos dramatização através de máscaras de alegria, tristeza, susto, e raiva.

Aqui a experiência que fez chorar a todos: uma aluna autista de 14 anos, que raras vezes falava, identificou-se com o personagem Chida e resolveu pegar a máscara - foram 15 minutos de pura emoção, onde falou da percepção de seu jeito diferente, do rechaço dos colegas, mas da disposição de aprender e ser gente e por isso insistia no estudo. Desatou num choro, pedi licença para tocá-la e poder abraçá-la e depois veio o abraço coletivo dos colegas e professoras.

A ideia inicial, era finalizar a atividade pedagógica do semestre, editando um livro geral, cada parte com um dos trabalhos dos alunos. Mas o empenho foi tão 
grande, que não tive coragem de descartar qualquer trabalho deles. Cada um recebeu seu próprio livreto - 8 folhas, tamanho A5, com desenhos e fotos coloridas.

O livreto individualizado, traz a explicação do projeto, foto do autor ou autora, lendas e folclore gaúcho e suas características; letra do Rap de autoria do aluno, trabalho artesanal dos galhos secos e descritivo da atividade de contorno dos corpos, teatro de máscara, dicas do personagem Teo, sobre comportamento em passeios e viagens, curiosidades sobre a Revolução Farroupilha e o registro fotográfico das atividades presenciais. Ainda hoje tenho contato com alguns deles. Dia do Professor recebi declarações comovedoras."

Estórias Diferentes conta com um site próprio. Lá, são encontrados cenários exclusivos feitos pelo artista de BD (histórias em quadrinhos) LEO, personagens idealizados por Cristina Oliveira e repaginados por Francisco de Oliveira Brasil, designer gráfico. Contém 3 áreas:

Floresta dos Rolls - aventuras, brincadeiras e conversas, onde se escuta o outro, expõe sentimentos. Área em que se trabalha conceitos como solidariedade, responsabilidade e inclusão. Onde se destaca a importância da leitura.

Acontece - textos curtos, informativos, contendo comemorações e datas úteis para trabalhos escolares.

Viagens do Teo - descritivo de locais visitados sob a ótica infantil. O olhar de uma criança, sua percepção e dificuldades em passeios e viagens. Há dicas de cuidado e comportamento na preparação e durante as viagens, para crianças e seus pais.

Portanto, o projeto Estórias Diferentes atua proporcionando um espaço de cuidado a crianças e adolescentes, com atividades lúdicas que promovem apoio e acolhimento em saúde mental. O projeto traz contos que podem ser adaptados e dirigidos a situações específicas, estando presentes em escolas, associações, e até mesmo em consultórios médicos, buscando aproximar adultos e crianças.

\section{Referências Bibliográficas}

DELFINI, P. S. S.; BASTOS, I. T.; REIS, A. O. A. Peregrinação familiar: a busca por cuidado em saúde mental infantil. Cad. Saúde Pública, v. 33, n. 12, 2017. 
MATSUKURA, T. S.; FERNANDES, A. D. S. A.; CID, M. F. B. Fatores de risco e proteção à saúde mental infantil: o contexto familiar. Revista De Terapia Ocupacional da Universidade de São Paulo, v. 23, n. 2, p. 122-129

TAÑO, B. L; MATSUKURA, T. S. Saúde mental infantojuvenil e desafios do campo: reflexões a partir do percurso histórico. Cad. Ter. Ocup. UFSCAR, São Carlos, v. 23, n. 2, p. 439-447, 2015. 